\title{
Neuroblastoma metastatic to the liver in infants
}

\author{
JANE V. BOND \\ From The Hospital for Sick Children and Institute of Child Health, London
}

\begin{abstract}
Bond, J. V. (1976). Archives of Disease in Childhood, 51, 879. Neuroblastoma metastatic to the liver in infants. Four infants are described who presented with rapid enlargement of the liver. This was found to be due to neuroblastoma which had metastasized to the liver; the condition was associated with high levels of urinary vanillylmandelic acid (VMA). In 3 infants the primary tumour was in the adrenal gland and in one it was not identified. One infant died after laparotomy and 2 infants survive disease free with normal VMA levels, one after adrenalectomy and hepatic irradiation and one after a short course of chemotherapy. The fourth patient responded initially to hepatic irradiation and chemotherapy, but relapsed 2 years later with recurrent disease; at the same time the VMA level which had been normal, again rose.

The importance of screening for an abnormal VMA level in any infant with a rapidly enlarging liver in order to obtain an early diagnosis is stressed. Careful follow-up, with serial VMA estimations, is essential to detect recurrent disease. The prognosis for some infants with this distribution of neuroblastoma which has metastasized to the liver, but not to the bones or orbit, is good.
\end{abstract}

Rapid enlargement of the liver in a young infant may be due to hepatoblastoma, lymphoma, metastatic neuroblastoma, or to any of the various nonmalignant causes of hepatomegaly. Diagnosis of hepatoblastoma may be confirmed by the abnormal liver scan which usually shows a space-occupying lesion; this is associated with an abnormally high level of $\alpha$-fetoprotein. In neuroblastoma there is diffuse infiltration of the whole liver by small metastatic nodules of disease, and the urinary vanillylmandelic acid (VMA) level is raised. Measurement of VMA is an extremely useful simple diagnostic test which, if positive, may eliminate the need for other more complex investigations (Bond, 1975). Bone marrow examination will exclude the diagnosis of leukaemia and may show infiltration with metastatic neuroblastoma cells.

Infants with neuroblastoma have a far better prognosis than do older children with the disease, provided that they do not have bone metastases. There is a small group of infants in whom the tumour presents with a particularly characteristic pattern of metastatic spread; this is associated with a very good prognosis and some of these infants require little or no treatment to initiate regression of disease (D'Angio, Evans, and Koop, 1971).

Received 20 February 1976.
The primary tumour is usually in the adrenal gland but may be elsewhere; metastatic spread is confined to the liver, skin, and occasionally bone marrow, without involvement of bones or orbit. Evans, D'Angio, and Randolph (1971a) suggested a staging for neuroblastoma (Table I), which classifies these infants as a separate group, known as stage IVs.

\section{TABLE I}

Staging for children with neuroblastoma (Evans et al., 1971)

\begin{tabular}{|c|c|}
\hline Stage I & Tumour confined to organ or structure of origin \\
\hline Stage II & $\begin{array}{l}\text { Tumour extending in continuity beyond the organ or } \\
\text { structure of origin but not crossing the midline. } \\
\text { Regional lymph nodes on the homolateral side may be } \\
\text { involved. }\end{array}$ \\
\hline Stage III & $\begin{array}{l}\text { Tumour extending in continuity beyond the midline. } \\
\text { Regional lymph nodes may be involved bilaterally }\end{array}$ \\
\hline Stage IV & $\begin{array}{l}\text { Remote disease involving skeleton, organs, soft tissues, } \\
\text { or distant lymph nodes }\end{array}$ \\
\hline Stage IVs & $\begin{array}{l}\text { Patients who would otherwise be stage I or II but who } \\
\text { have remote disease confined only to one or more of } \\
\text { the following sites: liver, skin, or bone marrow } \\
\text { (without radiographic evidence of bone metastases } \\
\text { on complete skeletal survey) }\end{array}$ \\
\hline
\end{tabular}




\section{Patients and methods}

Four infants are described who presented with rapid onset of hepatomegaly. This was found to be due to neuroblastoma which had metastasized to the liver. In 3 patients the primary tumour was in the adrenal gland, and in one patient it was not identified.

Case 1. A boy aged 8 weeks was referred with a 2-week history of vomiting and rapidly increasing abdominal distension which was found to be due to hepatomegaly. Intravenous pyelogram (IVP) was normal and no metastases were found on skeletal survey. There were no abnormal cells in the bone marrow. Urinary VMA was $31.9 \mathrm{mg} / 24 \mathrm{~h}(160 \mu \mathrm{mol} / 24 \mathrm{~h}$ ) (normal level at $<6$ months of age is $<1 \mathrm{mg} / 24 \mathrm{~h} ;<5$ $\mu \mathrm{mol} / 24 \mathrm{~h}$ ). At laparotomy a right adrenal neuroblastoma was removed and the liver was noted to be diffusely infiltrated with metastatic nodules. Hepatic irradiation was given (500 rads in 10 fractions), during which time the baby was unwell and fed poorly. There was no initial response to treatment though the general condition improved rapidly, but at 3 months the liver size had markedly decreased and at 6 months it was almost normal. At the same time the VMA level gradually returned to normal. The patient is well and disease free 4 years after completion of treatment, with a normal VMA level.

Case 2. A boy aged 6 weeks was referred with a 1-week history of vomiting and irritability. He was extremely emaciated with a grossly enlarged nodular liver. IVP showed no abnormality and there was no evidence of bone metastases. No abnormal cells were seen in the bone marrow aspirate. VMA level was $80 \mathrm{mg} / 24 \mathrm{~h}(400 \mu \mathrm{mol} / 24 \mathrm{~h})$ and there were also raised levels of homovanillic acid and cystathionine. Hepatic irradiation was given (500 rads in 10 fractions), during which time he was extremely unwell and required intravenous fluids because of poor feeding. He did not respond to treatment and continued to deteriorate. One month later he began to improve though the liver remained grossly enlarged. $\mathrm{He}$ was therefore given intravenous vincristine $0.25 \mathrm{mg}$ and cyclophosphamide $50 \mathrm{mg}$ on two successive weeks. At this time several skin nodules were noticed on the trunk, thought to be skin metastases. After another short course of hepatic irradiation he improved further and gained weight; at the same time the liver slowly regressed in size and the skin nodules disappeared. VMA level fell to normal. He remained well until 2 years later when an enlarged liver and a raised VMA level were again found, together with recurrent intra-abdominal and hepatic disease which did not respond to treatment.

Case 3. A girl aged 16 weeks was referred with a 4day history of poor feeding and frequent bowel motions. The abdomen was distended and the liver was extremely hard. IVP showed a calcified mass at the level of D9, and skeletal survey showed no evidence of bone metastases. Bone marrow aspiration was not carried out. VMA level was $6 \cdot 8 \mathrm{mg} / 24 \mathrm{~h}(34 \mu \mathrm{mol} / 24 \mathrm{~h})$. At laparotomy the grossly enlarged liver was biopsied and showed infiltration with metastatic neuroblastoma. She deteriorated rapidly and died 2 weeks later. Necropsy examination showed a left adrenal neuroblastoma which had infiltrated the left kidney, and metastatic involvement of the liver, pancreas, para-aortic nodes, and vertebral bone marrow.

Case 4. A girl aged 8 weeks was referred with a 1week history of rapid distension of the abdomen, but was otherwise well and feeding normally. She was found to have a large hard liver which was increasing in size daily until it nearly filled the abdominal cavity. IVP showed a duplex left kidney displaced by a calcified mass above it. Skeletal survey showed no evidence of bone metastases, and the bone marrow showed only occasional abnormal cells which were thought to be either neuroblastoma cells or lymphoblasts. VMA was $23 \mathrm{mg} / 24 \mathrm{~h}$ $(115 \mu \mathrm{mol} / 24 \mathrm{~h})$. Haemoglobin level was only $5 \mathrm{~g} / \mathrm{dl}$ so an immediate transfusion of packed cells was given, and at the same time fortnightly intravenous vincristine $0.3 \mathrm{mg}$ and cyclophosphamide $50 \mathrm{mg}$ were started. After the first dose the liver stopped increasing in size and by the sixth dose the liver was only just palpable. At the same time the VMA level gradually returned to normal. IVP showed that the left kidney was no longer displaced downwards and there was dense calcification at the level D12 and L1. She is well and disease free at 1 year.

\section{Discussion}

In 1901, Pepper drew attention to a condition in young infants which was characterized by the rapid onset of hepatomegaly associated with a tumour in one or both adrenal glands which he called congenital sarcoma of the liver and suprarenals. He reported one patient of his own and 5 other fully documented patients (Table II). From the clinical and pathological details given, these infants appeared to have adrenal neuroblastoma which had metastasized to the liver and which would now be classified as stage IVs neuroblastoma. The patients were all under the age of 2 months and the main finding was gross hepatomegaly in a previously fit baby; the enlarged left lobe of the liver was frequently mistaken for splenomegaly. There was no incidence of spontaneous regression of disease in this series of infants, all of whom died within a few weeks, becoming progressively more wasted and cachectic as the liver increased in size. At necropsy the primary adrenal tumour varied in size from being 'as large as a Tangiers orange' to 'as small as a walnut'. Histological study showed diffuse infiltration of the liver by a round cell sarcoma, which was similar in appearance to the primary tumour present in one or both adrenals. The tumour itself was exceedingly haemorrhagic. There was 
TABLE II

Six infants with congenital sarcoma of the liver and suprarenals

\begin{tabular}{|c|c|c|}
\hline Case no. & Sex and age & Sites of disease (post mortem) \\
\hline $\begin{array}{l}1 \text { (Parker, 1880) } \\
2 \text { (Meisenbach, 1884) } \\
3 \text { (de Ruyter, 1890) } \\
4 \text { (Heaton, 1898) } \\
5 \text { (Orr, 1900) } \\
6 \text { (Pepper, 1901) }\end{array}$ & $\begin{array}{l}\text { Girl } 3 w \text { (died } 5 w) \\
\text { Girl } 2 w(\text { died } 16 w) \\
\left.\text { Girl } 1 w \text { (died } 1 \frac{1}{2} w\right) \\
\text { Girl } 8 w(\text { died } 9 w) \\
\text { Girl } 7 w \text { (died } 16 w) \\
\text { Girl } 4 \text { w (died 61 w) }\end{array}$ & $\begin{array}{l}\text { Left suprarenal and liver } \\
\text { Liver } \\
\text { Both suprarenals and liver } \\
\text { Right suprarenal and liver } \\
\text { Both suprarenals and liver } \\
\text { Right suprarenal and liver }\end{array}$ \\
\hline
\end{tabular}

no involvement of any other organ or evidence of distant metastases.

Although the infants described by Pepper all died of their disease, there have been more recent reports of patients with stage IVs neuroblastoma in whom the disease has either regressed spontaneously or after minimal treatment (D'Angio et al., 1971; Schwartz et al., 1974). The clinical details of 7 patients who were reported to have survived disease free are summarized in Table III. While infants may recover from neuroblastoma which has metastasized to the liver, the prognosis is extremely poor if there are metastases to sites other than skin and bone marrow, such as orbits and bones.

The early diagnosis of hepatic metastases from neuroblastoma can be made by screening for inincreased VMA with the LaBrosse spot test (Evans et al., 1971b). The simple colorimetric test takes only a few minutes to perform and if positive can be followed by a quantitative measurement from a 24-hour urine collection. Response to treatment and regression of disease will be indicated by the gradual decrease in VMA level during the recovery period (Bond, 1975).

IVP may show an adrenal primary tumour, and if there are no metastases on $x$-ray skeletal survey the diagnosis of stage IVs neuroblastoma can be made with only a bone marrow aspiration to look for malignant cells. Regression of disease is indicated by the gradual decrease in size of the liver and falling VMA levels; at the same time if the IVP has originally shown an adrenal primary tumour, this may be seen to decrease in size on repeat $x$-ray and become increasingly more calcified.

Schnaufer and Koop (1975) reported 2 patients who had signs of venacaval obstruction and respiratory embarrassment due to a rapidly enlarging liver, and a temporary ventral hernia was constructed by means of a silastic pouch to accommodate the liver. This procedure is not without its complications and one patient died of postoperative septicaemia. It is probably safer to initiate regression with small doses of cytotoxic drugs. In a few infants who remain completely well throughout their disease, nothing other than careful observation may be required.

Wyatt and Farber (1941) reported 2 patients with hepatomegaly due to metastatic neuroblastoma who were initially successfully treated with irradiation of the large liver. However, one patient died 20 years later in renal failure, post-mortem examination of the kidneys showing radiation nephritis. The patient also had a basal cell carcinoma excised from the previously irradiated skin area.

TABLE III

Seven infants with stage IVs neuroblastoma

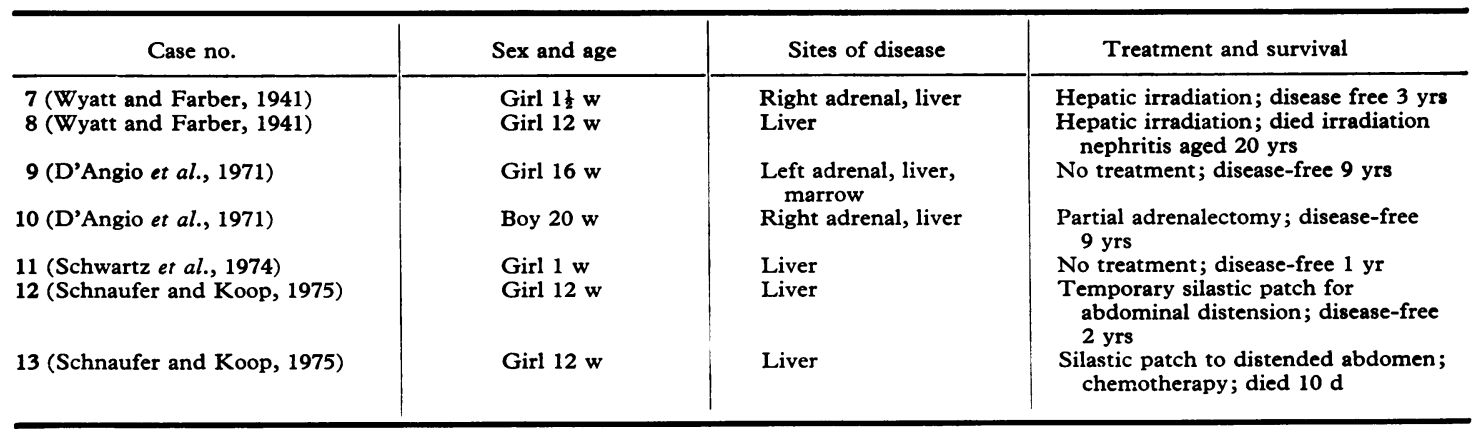


The use of irradiation in young infants is not without risk of complications and long-term morbidity, which is likely to be greater than in older children. In treating a grossly enlarged liver it is inevitable that at least the right kidney and possibly both kidneys will be included in the treatment volume. Onset of radiation nephritis may be insidious over many years, not becoming clinically evident until adulthood (O'Malley, D'Angio, and Vawter, 1963). Radiation tolerance of growing bones in young children is also low and there is considerable risk of permanent damage and later deformities if too high a dose is used (Neuhauser et al., 1952).

The most satisfactory reponse to treatment in this small group of patients was to fortnightly vincristine and cyclophosphamide for a period of 3 months, which stopped liver growth immediately, the liver also becoming much softer, and gradually decreasing in size over the next few weeks. Response to radiotherapy in the 2 patients in whom this treatment was used was not immediate and both were very unwell during treatment.

Because of the relatively benign nature of this form of neuroblastoma in some infants, it is important to make the diagnosis as quickly as possible and to assess the true extent of disease. If the liver continues to enlarge rapidly or the infant is generally unwell, then chemotherapy appears to be a satisfactory form of treatment, but once the liver has reduced in size all treatment should be stopped.

The fact that one patient relapsed nearly 2 years after complete regression of disease, during which time the VMA had remained normal, illustrates the need for careful follow-up with regular VMA estimations. It is unusual for a patient to relapse after such a long interval, during which time there had been no clinically obvious disease, but neuroblasto$\mathrm{ma}$ is an extremely unpredictable form of malignancy. The infant had been very ill before he finally responded to treatment, unlike the other 2 survivors who were generally very fit and did not lose weight or give the appearance of having generalized malignant disease.

I thank Dr. Philip Evans, Professor June Lloyd, and Mr. D. Waterston for permission to report details of patients under their care.

\section{REFERENCES}

Bond, J. V. (1975). Clinical significance of catecholamine excretion levels in the diagnosis and treatment of neuroblastoma. Archives of Disease in Childhood, 50, 691.

D'Angio, G. J., Evans, A. E., and Koop, C. E. (1971). Special pattern of widespread neuroblastoma with a favourable prognosis. Lancet, 1, 1046. de Ruyter, D. (1890). Congenital tumour of the liver and both suprarenals. Lagenbeck's Archiv für Klinische Chirurgie, 40. 98. Evans, A. E., D'Angio, G. J., and Randolph, J. (1971a). A proposed staging for children with neuroblastoma. Cancer, 27, 374.

Evans, A. E., Blore, J., Hadley, R., and Tanindi, S. (1971b). The LaBrosse spot test; a practical aid in the diagnosis and management of children with neuroblastoma. Pediatrics, 47, 913.

Heaton, G. (1898). Congenital round-celled sarcoma of the liver. Transactions of the Pathological Society of London, 49, 140.

Meisenbach, D. (1884). Myxosarcoma of the liver in an infant aged 4 months. Weekly Medical Review, St. Louis, 8, 433.

Neuhauser, E. B. D., Wittenborg, M. H., Berman, C. Z., and Cohen, J. (1952). Irradiation effects of roentgen therapy on the growing spine. Radiology, 59, 637.

O'Malley, B., D'Angio, G. J., and Vawter, G. F. (1963). Late effects of roentgen therapy given in infancy. American fournal of Roentgenology, Radium Therapy, and Nuclear Medicine, 89, 1067.

Orr, J. (1900). Sarcoma of suprarenal capsules in a child aged 7 weeks. Edinburgh Medical fournal, 8, 221.

Parker, R. W. (1880). Diffuse sarcoma of the liver, probably congenital. Transactions of the Pathological Society of London, 31, 290.

Pepper, W. (1901). A study of congenital sarcoma of the liver and suprarenals. American fournal of the Medical Sciences, 121, 287.

Schnaufer, L., and Koop, C. E. (1975). Silastic abdominal patch for temporary hepatomegaly in stage IV-S neuroblastoma. fournal of Pediatric Surgery, 10, 73.

Schwartz, A. D., Dadash-Zadeh, M., Lee, H., and Swaney, J. J. (1974). Spontaneous regression of disseminated neuroblastoma. Fournal of Pediatrics, 85, 760.

Wyatt, G. M., and Farber, S. (1941). Neuroblastoma sympatheticum. Roentgenological appearances and radiation treatment. American fournal of Roentgenology and Radium Therapy, 46, 485 .

Correspondence to Dr. Jane V. Bond, Institute of Child Health, 30 Guilford Street, London WC1N $1 E H$.

\section{Addendum}

Since the introduction of SI units, VMA levels have been expressed in $\mu \mathrm{mol}$ VMA excreted in the urine over 24 hours. Normal levels at different ages are given in Table IV.

\section{TABLE IV}

Normal range of VMA levels in childhood (SI units)

\begin{tabular}{c|c}
\hline Age (years) & $\begin{array}{c}\text { Upper limit of normal } \\
(\mu \mathrm{mol} \text { VMA } / 24 \mathrm{~h})\end{array}$ \\
\hline $0-6 \mathrm{~m}$ & $5 \cdot 0$ \\
$6 \mathrm{~m}-2$ y & $13 \cdot 5$ \\
$2-3$ & $14 \cdot 5$ \\
$3-4$ & $15 \cdot 5$ \\
$4-5$ & $16 \cdot 5$ \\
$5-6$ & $17 \cdot 5$ \\
$6-7$ & $18 \cdot 5$ \\
$7-8$ & $19 \cdot 5$ \\
$8-9$ & $20 \cdot 5$ \\
$9-10$ & $21 \cdot 5$ \\
$10-11$ & $22 \cdot 5$ \\
$11-12$ & $23 \cdot 5$ \\
$12-16$ & $28 \cdot 0$ \\
\hline
\end{tabular}
$24 \mathrm{~h}$.

Conversion: SI to traditional units-VMA: $5 \mu \mathrm{mol} / 24 \mathrm{~h} \approx 1.0 \mathrm{mg}$ / 